\title{
XVI.
}

\section{Ueber das lösliche Eiweiss der Fische.}

\author{
Von \\ Dr. yon Baumhawer. \\ (Scheikundige Onderzoekingen, $1 V$, s. 322.)
}

(Im Auszuge.)

Die Zusammensetzung des löslichen Albumins der Fische war bis jetzt noch nicht untersucht worden; ich wurde zur Untersuchung dieser Substanz durch die Resultate meiner Untersuchung über das Nuskelgewebe der Fische geführt, welchen zufolge ich annehmen musste, dass bei allen derartigen Analysen der. Schwefel - und Phosphorgehalt unrichtig bestimmt worden sei.

Ich wendete zu meinen Untersuchungen die Scholle (Rhombus barbatus N., Pliuronectes rhombus L.) und Schellfisch (Merlangus vulgaris, Gallus Merlangus L.) an. Zu diesem Zwecke wurde die Fleischmasse zerhackt und mit kaltem Wasser ausgezogen, der wãssrige Auszug filtrirt und darauf bei ungefihr $50^{\circ}$ zum Coaguliren gebracht. Die coagulirte Masse wurde Jarauf mit kochendem Wasser, Alkohol und Aether ausgezogen und bei $120^{\circ}$ getrocknet.

0,457 Grm. dieser Substanz aus Scholte liessen nach dem Verbrennen 0,0045 oder 1,00 p. C. Asche.

0,304 Grm. dieser Suhstanz aus Schetlfisch hinterliessen 0,0915 oder 0,50 p. C. Asche.

Die Schwefelbestimmung der Substanz aùs Schellisch gab mit Aetzkali und Salpeter 1,385, 1,352 und 1,246 p. C., im Mittel 1,314 p. C. Schwefel. Durch die Phosphorbestimmung iwurde die Abwesenheit des Phosphors dargethan.

Durch Behandeln der Substanz aus Scholle mittelst Salpetersäure und salpetersaurem Kali erhielt ich 1,03 p. C. S, während der Phosphorgehalt 0,72 p. C. betrug.

Das Coagulum wurde in kochender Essigsäure gelöst und Ammoniak hiuzugesetzt, so dass aber die Flüssigkeit noch sauer reagirte; der dadurch entstandene Niederschlag wurde mil sie- 
dendem Wasser, Alkohol und Aether ausgewaschen und bei $120^{\circ}$ getrocknet. Die Kohlenstorf-, Wasserstoff- und Stickstoffbestimmung wurden mit aus der Scholle erhaltener Substanz vorgenommen; diese Substanz hinterliess beim Verbrennen 0,37 p. C. Asche. Die Schwofel- und Phosphorbestimmung geschah mit der aus dem Schellfisch dargestellten Substanz.

Ich erhielt in 100 Theilen:

$$
\begin{array}{rrrrc}
\mathbf{G} & 54,44 & 54,34 & - & - \\
\mathbf{H} & 7,03 & 7,07 & \overrightarrow{-} & \overrightarrow{-} \\
\mathbf{N} & 15,93 & 16,01 & 15,51 & 1 \overrightarrow{5,67} \\
\mathbf{S} & 1,66 & 1,54 & 1,48 & -
\end{array}
$$

Das ursprūngliche Coagulunn wurde ferner in verdünnter Kalilauge gelöst, die Auflösung einige Zeit bei $90^{\circ} \mathrm{C}$. gehalten und darauf 48 Stunden lang ein Luftstrom hindurchgeführt. Nach dem Filtriren wurde der folgende Körper durch überschūssige Essigsäure gefällt, mit kochendem Wasser, Alkohol und Aether ausgezogen und bei $120^{\circ}$ getrocknet. In dieser Substanz konnte sowohl durch Erhitzen von Aetzkali auf dem Platinblech, wie durch Kochen mit Aetzkali und essigsaurem Bleioxyd nicht die geringste Spur Schwefel nachgewiesen werden. Die C-, II- und $\mathrm{N}$ bestimmung geschah mit der aus Scholle dargestellten Substanz, die 0,5 p. C. Asche hinterliess, die Scliwefelbestimmung aber mit dem aus dem Schellisch erhaltenen Körper.

Ich fand in 100 Theilen:

$$
\begin{array}{rrrrr}
\mathbf{C} & 54,57 & 54,83 & 54,65 & - \\
\mathrm{H} & 6,95 & \mathbf{7 , 0 0} & \mathbf{6 , 9 6} & - \\
\mathrm{N} & 14,68 & 14,59 & - & - \\
\mathrm{S} & 1,21 & 1,00 & 0,93 & 1,24 .
\end{array}
$$

Durch die angestellten Versuche ist sattsam bewiesen, dass in diesen Stoffen kein freier Phosphor vorkommt; die geringe Menge von phosphorsaurem Eisenoxyd oder phosphorsaurer Talkerde, die ich in einigen fand, ist nur der Anwesenheit von etwas phosphorsaurem Kalke in der Asche zuzuschreiben. Da ich nun mit Mulder annehme, dass der Schwelel in diesen Substanzen, ehe sie mit Kali behande!t wurden, als $\mathrm{S} N \mathrm{H}_{2}$ torkommt, der nach dem Behandeln mit Kali in $\mathrm{S}_{2} \mathrm{O}_{2}$ ubergeht, so lassen sich als Formeln für diese Substanzen folgende annehmen:

Für den in Kali gelosten und daraus durch Essigsảure gefällten Körper: 


$\begin{array}{cccc} & \text { Gefunden. } & \text { Aequivalente. } & \text { Berechnet. } \\ \text { G } & 54,72 & 720 & 54,70 \\ \text { H } & 7,01 & 560 & 7,06 \\ \text { N } & 14,67 & 80 & 14,16 \\ 0 & 22,61 & 226 & 22,87 \\ \text { S } & 1,13 & 6 & 1,21 \\ & \frac{100,14}{10,} & & 100,00\end{array}$

und daraus die Formel:

$20\left(\mathrm{C}_{36} \mathrm{H}_{2 \tau} \mathrm{N}_{4} \mathrm{O}_{10}+\mathrm{HO} 0\right)+3 \mathrm{~S}_{2} \mathrm{O}_{2}$;

lür den in Essigsäure gelösten und daraus mit Ammoniak gefällten Korper:

$\begin{array}{cccc} & \text { Gefunden. } & \text { Aequivalente. } & \text { Berechnet. } \\ \text { C } & 54,58 & 360 & 54,67 \\ \text { H } & \mathbf{7}, 08 & 282 & 7,11 \\ \text { N } & 15,65 & 44 & 15,57 \\ \text { O } & 21,16 & 104 & 21,03 \\ \text { S } & 1,52 & 4 & 1,62 \\ & \frac{1,52}{99,99} & & 100,00\end{array}$

und daraus die Formel:

$$
10\left(\mathrm{C}_{36} \mathrm{H}_{27} \mathrm{~N}_{4} \mathrm{O}_{10}\right)+4\left(\mathrm{~S} \mathrm{~N} \mathrm{H} \mathrm{N}_{2}+\mathrm{II} 0\right) \text {. }
$$

Die Grundsubstanz, die sich in diesen Körpern findet, ist demnach :

$$
\begin{array}{llll}
\mathrm{C}_{36} & \mathrm{H}_{22} & \mathrm{~N}_{4} & \mathrm{O}_{20}
\end{array}
$$

\title{
XVII.
}

\section{Wirkung der arsenigen Säure auf die Pflanzen.}

\author{
Von \\ Adolph Chatim.
}

(Annales de Chimie et de Phys. XXIII, 105.)

Wenn man an irgend einer beliebigen Pflanze einige Wurzeln blosslegt und dieselbe mit mehreren Litern einer Arseniklösung von $\frac{1}{2000}$ Gehalt begiesst, so wird sie fast nie in den drei ersten Tagen des Versuches unterliegen; ofters wird sie sich, nachdem sie krankhafte Erscheinungen, wie Stillstand des Wachsthums, gelbe Färbung oder selbst Vertrocknen der Blătter gezeigt latte, wieder erholen. 